Meta

Journal des traducteurs

Translators' Journal

\title{
Lexical Search Strategies in Translation
}

\section{Margrethe Mondahl et Knud Anker Jensen}

Volume 41, numéro 1, mars 1996

Le(s) processus de traduction / Translation Process(es)

URI : https://id.erudit.org/iderudit/003656ar

DOI : https://doi.org/10.7202/003656ar

Aller au sommaire du numéro

Éditeur(s)

Les Presses de l'Université de Montréal

ISSN

0026-0452 (imprimé)

1492-1421 (numérique)

Découvrir la revue

Citer cet article

Mondahl, M. \& Jensen, K. A. (1996). Lexical Search Strategies in Translation. Meta, 41(1), 97-113. https://doi.org/10.7202/003656ar

\section{Résumé de l'article}

Cet article traite de l'utilisation de stratégies de recherche lexicale en traduction par des étudiants adultes d'anglais, langue étrangère. La recherche fait suite à une analyse de l'utilisation, par des apprentis traducteurs, des connaissances grammaticales (voir Mondahl et Jensen 1989; Mondahl 1991). Les données proviennent d'une expérience où les sujets doivent penser à haute voix tout en traduisant et dont les résultats ont été soumis à une analyse qualitative. Les auteurs restreignent ici leur observation à 4 des 10 sujets de l'expérience et se concentrent sur les stratégies de recherche lexicale, sur la description du cadre cognitif à l'intérieur duquel les sujets travaillent. Une description des dijférents types de stratégies de recherche montre que les stratégies de reformulation et d'associations spontanées sont les plus employées par les sujets.
Ce document est protégé par la loi sur le droit d'auteur. L'utilisation des services d'Érudit (y compris la reproduction) est assujettie à sa politique d'utilisation que vous pouvez consulter en ligne.

https://apropos.erudit.org/fr/usagers/politique-dutilisation/ 


\title{
LEXICAL SEARCH STRATEGIES IN TRANSLATION
}

\author{
MaRgReTHE MONDAHL AND KNUd ANKer JENSEN \\ Copenhagen Business School and University of Ärhus, Denmark
}

\begin{abstract}
Résumé
Cet article traite de l'utilisation de stratégies de recherche lexicale en traduction par des étudiants adultes d'anglais, langue étrangère. La recherche fait suite à une analyse de l'utilisation, par des apprentis traducteurs, des connaissances grammaticales (voir Mondahl et Jensen 1989; Mondahl 1991). Les données proviennent d'une expérience où les sujets doivent penser à haute voix tout en traduisant et dont les résultats ont été soumis à une analyse qualitative. Les auteurs restreignent ici leur observation à 4 des 10 sujets de l'expérience et se concentrent sur les stratégies de recherche lexicale, sur la description du cadre cognitif à l'intérieur duquel les sujets travaillent. Une description des différents types de stratégies de recherche montre que les stratégies de reformulation et d"associations spontanées sont les plus employées par les sujets.
\end{abstract}

\begin{abstract}
The present article discusses the use of lexical search strategies in translation by adult learners of English as a foreign language. The investigation follows up on an analysis of learners' use of grammatical knowledge in translation (see Mondahl and Jensen 1989; and Mondahl 1991). The data are informants' thinking aloud protocols, which have been subject to qualitative analysis. The present article concentrates on four of the study's ten informants and is as such a pilot study. In the article we concentrate on lexical search strategies, on a description of the cognitive framework within which the informants work, a description of different types of search strategies, and on illustrating that the strategies of reformulation and spontaneous associations are the most common strategies employed by our informants.
\end{abstract}

\section{MATERIAL}

The present study is based on a translation from Danish into English. Four informants' thinking aloud data are used. These four informants are part of a larger group of informants - ten in all - who were recruited at two Danish institutes of higher education: the Copenhagen Business School and the Danish Civil Defence Corps Officers' Academy. The Business School informants' education focusses on correctness, consciousness-raising, and written competence whereas the Officers' Academy informants have concentrated on fluency and oral competence. Each institute was represented by five informants. Differing educational goals were assumed to result in different patterns of acquisition and in different results as regards the informants' information processing. In this article the aim is to discuss whether this assumption is true, and if we can identify differences in the information processing of our informants with regard to lexical search.

\section{METHOD}

All ten informants were asked to translate the same text. The text was a newspaper article, which was unknown to the informants. The text was subjected to a few changes: it was abbreviated, the syntax remained unchanged but a few very unusual terms were removed. 


\section{THE USE OF INTROSPECTIVE METHODS IN THE INVESTIGATION OF LEXICAL SEARCH STRATEGIES}

Introspective methods are assumed to be well suited for the analysis of informants' considerations in connection with problem solving (Ericsson and Simon 1987). It is, however, not an entirely uncontroversial method (cf. Lörscher 1991) and the resulting data may differ in quality and type. The informants do self-observation, i.e. observe their behaviour instead of verbalising thought processes (Lörscher 1991), comment on their own performance, i.e. make inferences instead of verbalising thought processes, or perhaps they just describe what they are doing, not what they think (self-report). We assume, however, that in a study which employs both thinking aloud and retrospection the chances of getting reliable data are good ( $c f$. Ericsson and Simon 1987).

During the last few decades introspective methods have been used in language research to investigate linguistic information processing. The methods have been used in studies of both receptive and productive processing, and from the middle of the $1970 \mathrm{~s}$ problem solving models have been the dominating models in studies of how human beings process linguistic knowledge (Færch and Kasper 1987; Börsch 1986 and Jääskiläinen and Tirkkonen-Condit 1991). The use of introspective methods primarily enables the researcher to identify the information processing used by an informant, or to put it in another way: to study what goes on in the informant's head (Krings 1986).

Ericsson and Simon (1987) state that thinking aloud is the direct coding of the conscious thought, the informant's immediate reaction and her immediate use of necessary knowledge in relation to problem solving. This means that analysed and unanalysed knowledge can be distinguished in data. When an informant verbalises relative to a problem Ericsson and Simon consider this proof that the informant makes use of analysed knowledge, i.e. heeded knowledge from long-term memory is accessible, if there is no verbalisation this indicates that unanalysed knowledge is used. A control dimension can be revealed as well: if the informant verbalises, the product (in this case the translation) is subject to control - to varying degrees - if there is not any verbalisation, information processing is automatic (see also Mondahl and Jensen 1989).

\section{MODEL OF ANALYSIS}

\section{Introduction}

The following theoretical section highlights a question one often asks when working with translation: how does the translator work when translating lexical items. We introduce a cognitive model (Mondahl and Jensen 1989 and 1992) to outline types of knowledge activated by our informants; to analyse our informants' use of strategies we use an outline of translation maxims and strategies based on Krings (1986).

\section{Knowledge structure}

Our starting point is that using a language is a complex skill which involves different types of knowledge. In the present context we are primarily interested in the types of knowledge involved in the carrying out of a particular skill and our model is therefore a production model. Knowledge is defined as knowledge in the broadest sense possible; this means that knowledge can be both analysed knowledge to which an informant has access and about which she can verbalise and unanalysed knowledge to which she has no direct access.

The model below starts with the basic features of our cognitive apparatus. First, our cognitive apparatus experiences the surrounding world and decides if incoming data are worth storing. This gathering and evaluation of incoming data take place on the basis of already stored information. If the incoming data are to be stored, the system has to 
establish a representation of the event in a person's memory. When it becomes necessary to recall the event, the system must be able to do so both quickly and effectively, irrespective of whether recall takes place in a controlled mode or automatically ( $c f$. Johnson-Laird 1988).

Our cognitive system has two types of ability. The first type stems from short-term memory where information from the surrounding world and recalled knowledge from established representations are stored for a brief period while they are part of an on-going line of thought; on-going lines of thought are found in the system's working memory; the second type stems from long-term memory where knowledge consisting of recalled information is stored.

Traditionally - and we follow this tradition - long-term memory is subdivided into two types of knowledge: declarative knowledge and procedural knowledge. The first type includes former events and other factual knowledge. Storage of declarative knowledge is assumed to take place in hierarchical, propositional networks; it is analysed knowledge to which an individual has conscious access and it is the type of knowledge for which she can account most thoroughly. Declarative knowledge is often referred to as active knowledge:

Analysed knowledge is assigned a propositional mental representation which makes clear the structure of knowledge and its relationship to other aspects of knowledge [...]. Because the structure is apparent the learner is able to operate on this knowledge by transforming it, comparing it to other events and using it as a means of problem solving. (Bialystok 1982: 183)

However, only part of an on-going line of thought takes place in analysed knowledge structures. Much mental activity takes place in unanalysed knowledge structures which are not hierachical, propositional networks. This is particularly the case with skills that have been acquired and used so often that an individual is no longer conscious about the way in which the skill is demonstrated. Traditionally this type of knowledge is termed procedural knowledge. Unanalysed knowledge structures are not an indication of any lack of systematicity, but the individual does not have direct access to the structure of the knowledge in question and as a result of this she cannot verbalise about it:

Unanalysed knowledge is the general form in which we know most things without being aware of the structure of that knowledge [...]. Although unanalysed knowledge is structured, the mental representation does not include access to that structure, and so transformations and operations on that structure are precluded. (Bialystok 1982: 182)

In contrast to declarative knowledge, procedural knowledge is holistic. Holistic knowledge enables the individual to both think and act in known routine situations. But an individual does not have access to the internal structure of procedural knowledge so this knowledge is not well suited for tackling new and unknown situations.

\section{Control}

In the preceding section we described the structure of knowledge representation, but in order to understand any given action we also need a description of the relationship between the knowledge types and the individual's control over the mental activity necessary to perform an activity. Here we distinguish between controlled and automatic information processing. The following description is based on McLaughlin (1987).

So far we have stated that knowledge can be analysed, but this type of knowledge is not activated until an individual directs her attention towards the propositional structure of the knowledge in question. 
[...] controlled processing [,] is [...] a temporary activation of nodes in a sequence. This activation is under attentional control of the subject and, since attention is required only one such sequence can normally be controlled at a time without interference. Controlled processes are thus highly capacity limited, and require more time for their activation. But controlled processes have the advantage of being easy to set up, alter and apply to novel situations. (McLaughlin 1987: 135)

Since the working memory has limited capacity, processing that requires attention will strain the system. Controlled information processing is sequential and time consuming. An evident advantage of this kind of information processing is, however, its flexibility. It is based on analysed, declarative knowledge which may undergo endless changes due to new input. Furthermore it is the basis of logical thinking and problem solving.

Automatic information processing does not require the attention that controlled processing requires and it is therefore not impaired by the limited capacity of working memory:

Automatic processing involves the activation of certain nodes in memory every time the appropriate inputs are present. This activation is a learned response that has been built up through the consistent mapping of the same patterns of activation over many trials [...] Once learned an automatic process occurs rapidly and is difficult to suppress or alter. (McLaughlin 1987: 134)

Automatic information processing utilises procedural knowledge. The evident advantage is speed since many pieces of information can be processed simultaneously. The processing does not require much mental effort and thus makes room for the more capacity demanding controlled information processing. The price paid is lack of flexibility and limited use since this type of knowledge can only be applied in routine situations. Furthermore, what is characteristic of this type of knowledge is that it is difficult to change once it has been learnt and that if changes are required this means new training. On the other hand, it is possible to generalise from already incorporated knowledge of this type to new data within the same field of knowledge. This generalisation is built on recognisable regularities in the incoming data.

\section{Production}

We can now describe the relationship between declarative and procedural knowledge and the activation of this knowledge in connection with the carrying out of a skill. This section is based on Anderson (1985), Rasmussen (1987), Glahn, Jensen and Jensen (1988) and Mondahl and Jensen (1992), who all establish three levels of knowledge.

One extreme is the intellectual level. At this level a skill is carried out on the basis of analysed, declarative knowledge and the information processing is controlled. The informant has to concentrate on analysed knowledge structures. We term this level of information processing knowledge-based processing, because knowledge is used in the narrow sense of know-why. Selection of a plan, which determines the action to be taken, is made on the basis of a clear identification of the problem area. In (foreign) language production this means the introduction of metalinguistic knowledge. The other extreme is the level of skill-based processing. No conscious selection of plan takes place here; action is triggered automatically by certain signs in the input. The knowledge applied is fundamentally different from knowledge-based knowledge, it is holistic and cannot be verbalised in the propositional language of that processing. Knowledge here takes the form of know-when.

Between these two extremes we find creative, analytic information processing. This type of information processing is based on experience. It is characterised by the conscious combination of automised subroutines. Knowledge of this type comes into 
existence partly as the result of the repeated use of knowledge-based knowledge, partly as the result of the generalisation of procedural knowledge. In the first case, compilation of explicit rules takes place, i.e. they are completely or partly forgotten when they are no longer necessary. In the second case, choices are made on the basis of experience from comparable situations; the informant has established a set of practical rules which will lead to the desired result in most cases without an in-depth analysis of the conditions applying to their use. These rules are rules-of-thumb and the knowledge applied is of the know-how type.

Conclusions about the model of knowledge representation

Our knowledge representation model now has the following characteristics:

1) DECLARATIVE KNOWLEDGE

PROCEDURAL KNOWLEDGE

2) knowledge based know why

3) controlled analysed

1) knowledge structure

2) knowledge application

3) access to knowledge

Figure 1: Model of knowledge representation

Knowledge of the three types outlined above - structure, application and access is essential in translation. Automised, skill-based, procedural know-when knowledge is important in the lower levels of production, i.e. the elements of the translation where an informant has stored patterns of behaviour which are triggered by certain patterns/elements in the task, e.g. the use of the third person singular -s. Partly controlled, experience-based know-how knowledge is applied in routine problem situations and controlled, knowledge-based, declarative knowledge is applied in problem solving on the basis of the metalinguistic knowledge of analysed symbol systems.

\section{GENERAL TRANSLATION MAXIMS}

The general division into two basic knowledge types - declarative and procedural knowledge - can be identified already in a translator's approach to a translation task: it is revealed in the extent to which the translator applies analysed knowledge and controlled procedures in her problem solving. We term these procedures translation maxims (Krings 1986). They can be identified in the routines used by the translator and can be characterised as follows:

1. does the informant read the entire translation text before translating?

2 . does the translator note down (mentally or on paper) points of controversy when reading the text for the first time?

3. does the translator consider potential readers of the text?

4. is verbatim translation the translator's goal?

5. is the translation linear or circular - i.e. does the translator progress without returning to already translated passages or does she return to already translated text for reference and changes and is she willing to make changes?

6 . does the translation focus on form or on content? 
According to Krings (1986) translation maxims mirror the type of know-how developed by the individual translator in relation to doing translations, her translation competence and how she makes use of it. A translator may choose to use certain translation maxims or she may be influenced by maxims acquired through practice. We assume that the use of translation maxims is closely related to the type of instruction/acquisition that the translator has been exposed to.

\section{Translation sequences}

The translation process itself can be divided into two main categories: spontaneous sequences and problem sequences. The spontaneous sequences are characterised by the absence of stops/interruptions and by no overt signs of problems. During these sequences the translator applies her automised, skill-based knowledge (know-when) and the most automised elements of her experience-based knowledge. In thinking-aloud protocols, these sequences are characterised by the absence of verbalisation or by verbalisation that does not contain any signs of a problem-solving approach to the element in question.

Problem sequences are - in contrast to spontaneous sequences - characterised by stops/interruptions in the translation process. The translator's automised skill- and experience-based knowledge are no longer sufficient and she has to change to a more controlled type of processing which draws on analysed knowledge i.e. controlled experience-based or knowledge-based knowledge.

In an analysis of translation competence, different indicators can be applied to identify problem sequences. The primary indicator is a translator identification of the problem, i.e. the translator points out the problem directly or indirectly and verbalises about it. However, there are also several secondary indicators that show that the translator senses that something is problematic, for instance when she makes competing suggestions for the translation of the same source text element, underlines elements of the source text, is dissatisfied with the translation chosen, makes corrections, or pauses. These secondary indicators normally appear together. ${ }^{1}$

Focus in the following analysis is on a closer investigation of problem sequences. Basically, translation problems are either of a receptive or productive type. Receptive problems relate to the interpretation of the source text. The text used in this investigation did not contain many problems of this sort, but as we can see from our analyses below the interpretation selected nevertheless influences the final product.

In the present context, it is more interesting to look at production problems, however. Production problems are problems related to the production of the target language text and this is where we find that controlled search strategies are applied.

\section{THE SEARCH STRATEGIES OF PROBLEM SEQUENCES}

Production search strategies can be divided into two types: achievement strategies and reduction strategies. ${ }^{2}$ An achievement strategy is characterised by the translator's attempt to remain as close to the source text as possible, i.e. to retain the communicative goal of the primary text producer. There are four types of achievement strategies. First, the spontaneous association which resembles brainstorming. The translator is well aware that she is faced with a problem and she operates on the basis of associations which come to her spontaneously; she scans the field and may retrieve several possibilities that she has to choose from ( $c f$. next section: Evaluation Strategies). The second type of achievement strategy is the situational search strategy. Here the translator tries to solve a problem by referring to previous experience - translation and/or life experience in general; she makes detours in order to solve the problem and she manipulates the elements in order to reach an acceptable solution. The third type of achievement strategy is the reformulation 
of the source text in either the translator's $\mathrm{L} 1$ or L2 - a reformulation that the translator feels does not change the overall meaning of the element; the need for deliberation increases and the translator has to consciously consider the degree of equivalence obtained. Finally the translator may have to resort to problem analysis as such. Achievement strategies are characterised as ranging from experience-based, utilising know-how knowledge (i.e. the spontaneous association) to knowledge-based, utilising know-why knowledge (i.e. problem analysis). The spontaneous associations of the problem sequence differ from unproblematic, uninterrupted spontaneous sequences in that they demand the translator's attention. In these cases the translator is aware that there are several options and that she has to make well-argued decisions.

Reduction strategies are characterised by the translator's inability to find an acceptable translation equivalent: she has to simplify form and/or content. Simplification at its most extreme simply means not translating the element in question, less extreme options being the selection of a neutral style instead of the marked style of the source text (or vice versa) or avoiding the use of idiomatic expressions. The result of this is a linguistically correct but perhaps less precise translation. The willingness to select reduction strategies is related both to the translator's linguistic competence and to her translation maxims.

\section{Evaluation strategies}

When the translator is faced with several options she has to make choices. She may evaluate on the basis of a spontaneous reaction such as. "this sounds better" - a strategy often used by translators who prefer using spontaneous associations. If on the other hand the translator chooses to use rules and to control her choices she will usually use less intuitive evaluation strategies. Among these strategies we find, for example, attempts at identifying differences between the source text and a potential translation equivalent. Acceptability may come in here, and statements like "this is certainly not correct" may be found in informants' protocols. The translator may also test adequacy by "translating back" to the source language in order to check whether the two expressions are similar, or she may consider who the readers of her translation will be. Finally, choices may follow the translation maxims adhered to by the translator.

Below we analyse four informants' translation processes. The analysis is based on four protocols selected from a total of ten protocols (see Mondahl 1991). Table 1 gives an overview of the informants' utilisation of the categories established above.

\section{Analyses}

The analysis of the four informants' lexical search strategies focuses on their solutions to problem sequences and the related evaluation strategies. The informants' spontaneous associations are also included but not discussed as thinking-aloud data are only available in the form of self-report here. In the problem sequences we have access to thinking-aloud data on thought processes since the informants verbalise thought processes relating to the elements of their translation - the problem areas - that demand more than just an automatic response.

\section{INFORMANT 1}

This informant belongs to the group of officers. In our investigation of grammatical competence he fits into the category of informants who primarily use experience-based knowledge. The protocol has a good deal of verbalisation both with respect to self-observation data and self-report data. The informant's translation maxims make him work as follows: he translates paragraph by paragraph, i.e. he reads the paragraph and translates a word and/or phrase at a time without going back and forth between paragraphs; the text is 
processed once and he solves problems as he encounters them. The informant experiences the text as part of a research project, not as a genuine piece of information that he has to translate for the benefit of potential readers. He does not take notes while reading the text and the translation is linear. The purpose of reading the text may be hard to see as the informant does not use it for the identification of problem areas; he may, however, do so in order to identify potential grammatical problems rather than lexical problems; his thinking aloud points in this direction since it contains several references to syntax and the possibilities of using parallel syntax in Danish and English. The informant does not consider text-type, style, or level of formality.

It is characteristic of the informant's verbalisation that it is relatively brief and without many arguments for or against a chosen solution, i.e. it often verges on self-report. The fact that thinking aloud takes place indicates that an element is problematic, but often the verbalisation remains a report, e.g. that "this is probably the correct expression." This clearly indicates the informant's use of experience-based and skill-based knowledge.

Now let us turn to the individual sequence types. The informant frequently uses the spontaneous sequence strategy, and he does not return to these sequences. His starting point is that there must be a one-to-one correspondence between the source text and the target text. He verbalises in some of the sequences, but this verbalisation is a self-report rather than a verbalisation resulting from a problem-oriented approach to the issue. In these sequences he uses skill-based knowledge only.

example $1 \ldots$ decide on something - that is: make a decision... ${ }^{3}$

As regards achievement strategies, the informant often uses the spontaneous association in problem sequences. The informant utilises experience-based knowledge in combination with skill-based knowledge, he uses target language characteristics: "this sounds better," source language elements: "this is more precise" and interpretations of the word(s) that is/are to be translated.

The informant evaluates his spontaneous association solutions using evaluation strategies like acceptability, precision and his translation maxim of remaining as close to the original text as possible.

example 2... British/French. On the face of it I think I prefer: French/British it sounds better, but when it says like this I suppose I'd better...

As regards the situational search strategy the informant uses world knowledge and is able to draw parallels with expressions that he knows from other contexts. He does not really evaluate the solution but accepts it without further consideration.

example $3 .$. air companies - I seem to remember something like aviating companies, air companies? airlines of course. British Airways, Western Airlines - we'll use airlines...

The use of the reformulation strategy occurs both in English and in Danish; the informant makes the decision to use or discard the option in question by considering acceptability, closeness to source text and one-to-one correspondence. He uses experience- and skill-based knowledge in combination, thus making procedural knowledge a prominent element of his information processing. Results are evaluated on a procedural knowledge basis: he uses criteria like acceptability, meaning, or no overt strategy at all. An interesting feature is that once the informant accepts a reformulation, he accepts that one-to-one correspondence is not a must, and he thus chooses to translate something which is not clear in the source text into something which is clearer.

example $4 .$. carefully surveyed - I'll change that into: it will be carefully surveyed... 
Finally there is the problem analysis strategy. We only find very few attempts at problem analysis, and not very consistent ones. The informant tries to give reasons, to analyse the sentence and he tries to apply linguistic knowledge. He evaluates using the criterion of meaningfulness.

example 5... asking at the moment - are they asking themselves? $\mathrm{No}$, I don't think so; if that is the case it must be translated into: ask themselves. No, I don't think they are asking themselves, it more of a demand, so we can use demand then...

The reduction strategy is applied in situations where the informant clearly wishes that he had access to dictionaries, for example, when he is at a loss and has to accept solutions that he is not satisfied with.

example $6 .$. international fleet of aircraft - we'll change that into an of-construction... well, fleet of aircraft - I cannot make a direct translation of that but we can use potential here - potential - aircraft potential maybe. I would look up something like this...

\section{Conclusions about Informant 1}

The informant has many spontaneous sequences and a good deal of problem sequences that are solved by the introduction of the spontaneous associations strategy. The number of situational strategies and reduction strategies is lower than the number of spontaneous associations (see tables 1 and 2) and these strategies are typically followed by evaluation strategies of the "does this sound OK" and "is this precise enough" types. As regards the last point, we find a variation within the evaluation strategies used: the more conscious the informant is about what he does to solve a problem, the more liable he is to accept distance between source and target language text. The informant does not consider group of readers, stylistic features or contrast/comparison between Danish and English, but relies on intuition.

\section{INFORMANT 2}

This informant also belongs to the group of officers. In our investigation of grammatical competence he belongs to the group who almost exclusively use skill-based knowledge. The protocol does not contain much verbalisation, but in the retrospection session, which was carried out immediately after the thinking aloud, the informant provides us with more information on his reasons for selecting certain lexical items rather than others. The obtaining of this information was further facilitated by replaying the video from the thinking-aloud session. Both the thinking-aloud verbalisation and the retrospection contain self-report and self-observation data; most of the data, however, are self-report data. One may wonder why this is the case. The informant received exactly the same introduction to and information on the task as the other informants, but apparently he was of the opinion that he was to solve the task as fast as possible. This left him very little time and room for elaborate considerations even though he might have performed a more in-depth analysis more often than he actually did. From the retrospection it is clear that some of the verbalisation has been omitted on purpose, i.e. the informant monitors his verbalisation and claims that he does not have anything sensible to say about his actions. This may be true in the sense that he primarily uses skill-based knowledge. It is clear, however, that some problem-solving strategies are not verbalised; this comes out in the retrospection where he explains that in some cases he did not know what to do, and therefore he did not say anything even though he did produce a translation of the item in question. This highlights one of the drawbacks of the thinking-aloud method: some informants will - unfortunately - monitor their verbalisation; the thinking aloud therefore 
becomes a self-report rather than a rendering of thought processes, and reliability is reduced. Compensation is obtained, however, by the use of retrospection data.

It is characteristic of the informant's verbalisation that it is brief. He states what he does, accepts his solution and goes on to the next point. He makes quick, straightforward decisions, e.g. "corridor, that is probably the same in English" and he does not make any overt evaluation of a decision. When he verbalises, it is either because he is not quite sure that he has got it right and wants to hear if it sounds correct, or because he feels that he has to say at least something, and he then naturally verbalises when he has encountered problems. When problems occur, the informant uses skill-based knowledge to solve them; there are only a few examples of the introduction of experience-based knowledge. Translation is linear, no underlining of problem areas takes place, he reads the text aloud before translating - probably out of habit. He does not consider text type, level of formality, style, or group of readers.

Now let us turn to the individual sequence types. As indicated above, the informant's translation maxims point in the direction that he will avail himself of skill-based knowledge, perhaps in combination with experience-based knowledge. As regards the spontaneous sequence strategy, the informant uses this strategy quite often, he does not return to the solutions selected and we do not get to know if he applies any evaluation strategies in these cases. He introduces skill-based knowledge and accepts the results that the application of this knowledge provides him with.

example $7 \ldots$ and here we'll use fall...

With regard to the achievement strategies, we find that the majority of these strategies are spontaneous associations based on the activation of experience-based knowledge in combination with skill-based knowledge. Here the informant uses acceptability in English as the evaluation yardstick.

example $8 \ldots$ begins - I guess we could use starts...

The situational strategy is used on a couple of occasions, primarily in the form of world knowledge, but evidence of why this strategy is selected is scarce. The informant compares with Danish terminology and assumes a one-to-one correspondence.

example $9 \ldots$ bang - what the hell is the word for that? well, boom looks similar anyway...

Reformulation is used primarily in English; on one occasion the informant reformulates something which he believes to be rubbish in Danish into something which can be understood in English. Generally speaking, however, the informant does not seem to worry about translating something which does not make sense into something which does not make sense either.

example $10 \ldots$ I'll use tests instead of they because you have to consider what it is going to refer to...

We find no examples of problem analysis - not even in the retrospection, where researcher questions could have inspired the informant to make a more in-depth analysis of a problem. Probably the informant does not command the knowledge-based knowledge this requires.

The reduction strategy is used on a number of occasions, but the informant only verbalises about it on one occasion. It is, however, clear that reductions are a part of his approach, and the final translation contains several examples of an item having been left out entirely or the use of a very general term. It does not seem to worry the informant; it is clear that he does not consider the task a piece of real life communication where he will have to come up with something. He accepts that there are things that he does not 
know, says that he would have looked it up, if he had been given the chance and then leaves it at that.

example $11 \ldots$ fleet of aircraft - well, I'll have to look that one up...

\section{Conclusions about Informant 2}

This informant highlights the influence of the attitude to the task set in comparison with the information we get. Clearly the informant approaches the task as part of a study and never involves himself in task solution to the extent that some of the other informants do. His linguistic knowledge is of the skill-based type. Apparently he does not command much experience-based knowledge and hardly any knowledge-based knowledge. His favourite strategy is the spontaneous sequence strategy. The achievement strategies activated are the spontaneous association and the reformulation, and only very rarely one of the other strategies. Evaluation strategies are hard to identify, but the ones used are of the acceptability type.

\section{INFORMANT 3}

This informant was a Copenhagen Business School student at the time of the test. She was doing her last year before taking her master's degree in specialised language for business. The informant uses the following translation maxims: she reads the text and comments on potential problem areas as she proceeds. During this first reading she considers a potential target group several times - she does not know anything about the text except that it has been taken from a Danish newspaper. Thus she is not able to specify in detail who her readers will be, and she chooses to solve this problem by selecting a neutral style. She often works in a circular fashion; after having read the text she goes through the text twice utilising what she has already translated later in the text and revising the beginning as she makes alternative decisions further on in the text. She also uses different approaches simultaneously to the same problem, e.g. reformulation in combination with problem analysis or situational associations. She states that she has an overall translation maxim that tells her to make as literal a translation as possible, but she often goes against this maxim and changes the text considerably in order to make it work in English. In other words: she has a translation maxim she often does not follow - at least not in a consistent way. In some cases she translates what she considers rubbish directly into something which is not good English either, in other cases she decides to improve the text in order to produce a good English text.

Now let us turn to the individual sequence types. The informant uses very few spontaneous sequences and this matches her overall approach. Her spontaneous sequences are characterised by the application of skill-based knowledge without verbalisation; sometimes she verbalises just in order to say something as the following example shows.

example $12 \ldots$ the autumn - not the spring...

In accordance with this we find that the informant does not use spontaneous associations very often. When she uses them, she only verbalises with a view to hearing if it sounds OK. In these cases she evaluates her search strategy by checking if the solution conveys the meaning that she intends to convey. She says, for example, "this is not any stranger in English than it is in Danish..."

example 13 ... during the next few weeks - I am not too happy about this but... 
In her use of the situational search strategy the informant uses her world knowledge to the fullest. She sees the translation as a problem solving task where experience from other or similar situations can be used as adequate search strategies.

example 14... well, the Anglo-French Concorde - I guess I'll have to use a hyphen, and then there is a $-d$ in Concorde, because they make a joke about that in "Yes, Minister"...

The reformulation is the search strategy used most often by the informant. She uses the strategy both in English and in Danish, often in combination with other strategies. She operates in a circular fashion and her approach is controlled and based on analysed knowledge. She often has several options at her disposal, and in these cases we find that although her approach is that of experience-based knowledge her evaluation is often based on skill-based knowledge, i.e. does it sound acceptable? We do find, however, that she uses comparison, contrast and style in her evaluation of solutions based on reformulation.

example $15 \ldots$ what a supersonic bang will say - that is nonsense in Danish - a bang cannot say anything - I'll just write what a supersonic bang is because that covers the same meaning: the British will experience - no, I cannot write what a supersonic bang is - that's no good - I can of course say experience a bang... I'll write the something or other - of a supersonic bang...

Finally there is the problem analysis strategy, which is not used very often by the informant. There are two instances in all and they relate to two specific problems in the text. In these two cases reformulation and/or paraphrase are not possible, the informant does not know the precise term and she has been told to translate the element. She tries to approach the problem from different angles, but none of the solutions that she can think of satisfy her completely. She has to accept solutions that are not ideal, and in one of the cases she ends up using a reduction strategy.

example $16 \ldots$ and then it says English workers, this means that the text distinguishes between British/French and English, then I'll have to say English here, then I suppose they can come from all over the place...

As indicated above there is one instance where the informant has to introduce a reduction strategy. In this case she has to accept the use of a neutral term rather than the more precise one.

example $17 \ldots$ his supersonic bang - here I would have gone into the kitchen and had a cup of coffee and I would have thought about something totally different for 10 minutes... they are going to experience a bang meaning - - I really think that it means something that they are going to experience a supersonic bang, and I'd rather write that than change the whole construction which I don't like anyway... it is better to expand the text a bit and write something which is correct than to write some rubbish just because I have to stick to the source text...

\section{Conclusions about Informant 3}

The informant uses experience-based and knowledge-based knowledge in her approach to the problems that she has to solve. She evaluates her solutions by introducing stylistic features, target group expectations, acceptability, contrast and comparison. One of her problems is that she is not always able to follow her general approach of trying to make as literal a translation as possible. This creates inconsistencies between sections of the text where she chooses to keep what is actually non-sensical and other sections where 
she makes alterations for the benefit of the reader. This does not seem to be a conscious decision; it is rather the result of the knowledge available to her in the particular case.

\section{INFORMANT 4}

This informant belongs to the group of Copenhagen Business School informants. Like Informant 3 she was doing her last year before taking her master's degree in specialised language for business.

The informant uses translation maxims that make her read the text first, identify word order problems and other syntactic problems, and then look up difficult words before translating anything at all. She has no dictionaries this time, so she is faced with a situation where she has to use her own resources and evaluate decisions made on the basis of the knowledge available to her here and now. She states that instead of using a dictionary she will try to solve the problems as she goes along, but does not quite stick to this. Instead she takes up previous points both during her first attempt at translating and during the following revision. She works in a circular fashion, using already made decisions later in the text and altering previous decisions, in these cases she also considers stylistic variation. After completing the first version of her translation, which has blanks, question marks and preliminary suggestions, she starts all over again, makes a few corrections and tries to fill in the blanks. Her translation maxims include a maxim that tells her to remain as close to the text as possible. Like Informant 3 she has problems with this. When she considers the Danish text clumsy or even rubbish, she is in doubt as to the legitimacy of making more drastic changes. She has no consistent approach to this problem.

Now let us turn to the individual sequence types. The informant uses the spontaneous sequence strategy on a small number of occasions. She works in a controlled fashion, however, that prevents her from using this option except in situations that are completely uncontroversial.

example 18 ... supervised by - I'm quite sure about that..

In contrast to this, we find that in problem sequences she often avails herself of the spontaneous association. She verbalises about many items not only in the form of selfreport but also in the form of self-observation, and from these self-observations it is clear that the spontaneous association is used often. She makes the assumption that there is a one-to-one correspondence between Danish and English in these situations. Her evaluation is based on an acceptability judgement in these cases.

example $19 \ldots$ I am going to translate this into are asking not just ask...

As regards the situational search strategy we find that she only uses this strategy on a few occasions and with no positive result. In cases where it would have been natural to draw on other texts, or situations, or use world knowledge in general, she does not do so, but remains "within" the text for clues that might help her. Again evaluation is based on an acceptability judgement - does this sound English?

example $20 \ldots$ speed - there are other words for that, but in an ordinary text speed is probably all right...

Together with the spontaneous association the reformulation strategy is her most frequent strategy both as regards single words, phrases and entire sentences. She reformulates in English but often introduces only two options that she will have to choose between. The strategy is useful, but she finds it difficult to accept that she cannot check her (very sensible) solutions in some sort of reference book. She is used to this and it makes her uneasy that her means of evaluation have been limited to her own resources. 
example $21 \ldots$ during the coming, the next weeks, it may be the coming weeks, next sounds? next few or coming - it doesn't sound good. No, I think I'll write the coming - no, I'll write in the next few weeks.

We find four examples of problem analysis in the protocol. The analysis is not a very deep and thorough one, but she activates knowledge-based knowledge that assists her in the solution of - in particular - phrases and whole sentences. Evaluation of correctness is again limited to an acceptability judgement and she is therefore left in doubt as to the adequacy of her solutions.

example $22 \ldots$ in the coming weeks - there is something about in I don't know if it is going to be during or in, I believe it is during when it means now and then...

We find some examples of the introduction of the reduction strategy. The use of this strategy is probably linked to the fact that she is used to checking everything, she commands the reformulation and problem analysis strategies but not sufficiently well for solving all problems, and as she is not able to combine different strategies and try all over again, she leaves problems either partly solved (using a neutral term) or with no solution at all. This is of course only possible because she knows that this is a study not a real life piece of communication.

example $23 .$. then learn - you cannot use too concrete an expression here. I'll just leave a blank here... find out for learn, I think...

\section{Conclusions about Informant 4}

Informant 4 primarily uses experience-based and knowledge-based knowledge in her solutions to the problems that she encounters in the translation. The two most prominent strategies are the spontaneous association and the reformulation, but problem analysis comes in more often than with any of the other informants. Her main problem is that although she commands both experience-based and knowledge-based knowledge she does not command a variety of evaluation strategies. This is a serious drawback for her. Her translation is influenced by this as her ability to decide on one option is not good enough. Accessible production knowledge is not enough, accessible evaluation strategies are also necessary. Her translation is influenced by a host of translation maxims that she seems to have learnt, she does not adhere to them in a consistent way and they hinder rather than help.

\section{CONCLUSIONS}

In the present article we set out to investigate four informants' information processing of lexical items. We have described our methodological approach - think aloud and retrospection protocols, the advantages of access to the direct coding of the conscious thought and the drawbacks of the informants' monitoring of their verbalisation resulting from their fear of saying something wrong. We have outlined a cognitive framework of two different knowledge structures (declarative and procedural knowledge), three ways of applying linguistic knowledge (knowledge-based, experience-based and skill-based knowledge) and two types of access to linguistic knowledge (controlled and automatic).

We have analysed four informants - two from each of our two groups and these analyses show that there is individual variety, but also some degree of resemblance between the informants who belong to the same group. The two business school informants clearly utilise much more knowledge-based and experience-based knowledge than the two officers' academy informants, who use more skill-based knowledge. The differences between the four informants emerge most clearly with regard to the introduction of evaluation strategies. Here informants 1 and 3 are very able users of different evaluation 
strategies whereas informants 2 and 4 are not able to evaluate their own results to the degree necessary. This highlights the need for good evaluation strategies in combination with good search strategies, which will not do the job alone. Informants' translation maxims are the clearest examples of differences between the two groups. The two officers have not got a host of translation maxims that they believe they have to live up to, whereas the two business school informants try to live up to a lot of different maxims - a hopeless task that only frustrates them as translators.

If we take a look at the categories of search strategies employed by the informants, we find that the most common strategy is the spontaneous association of the problem sequences (see tables 1 and 2). This indicates that problems are identified and solved on the basis of experience-based knowledge that can be activated quickly and automatically by the translator. The translator identifies a problem area, considers it briefly and makes a decision. The second most used strategy is the reformulation. This strategy is probably popular because it enables the translator to create some distance to the source text without changing it too much - it leaves room for guessing but within limits. It is interesting that the two categories used most are of the experience-based knowledge type; here we can assume that the informants have acquired knowledge either via know-why processing or via know-when processing, and in both cases the result is the easily available experiencebased knowledge that the informant can only explain very little about.

The present investigation discusses four informants only, there are common trends but also clear differences between these informants. It is not possible to conclude whether the observations made and the likenesses and differences identified will also apply to other informants that the ones analysed in this study; the study of grammatical competence carried out with the same two groups of informants (ten in all) showed that likenesses and differences were consistent throughout the groups, a reasonable assumption is therefore that this will also be the case in a study of lexical competence. Only further research and the study of more informants will confirm or discard this assumption.

\section{OVERVIEW OF INFORMANTS' USE OF LEXICAL SEARCH STRATEGIES}

\begin{tabular}{|lcccc|}
\hline & Inf 1 & Inf 2 & Inf 3 & Inf 4 \\
spontaneous seq. & 11 & 8 & 1 & 10 \\
problem seq. & 19 & 17 & 26 & 27 \\
\hline
\end{tabular}

Table 1: Informants' search strategies.

\begin{tabular}{|lcccc|}
\hline Problem sequences: & Inf 1 & Inf 2 & Inf 3 & Inf 4 \\
- spont. ass. & 11 & 8 & 5 & 10 \\
- situational & 1 & 2 & 3 & 2 \\
- reformulation & 4 & 5 & 14 & 6 \\
- problem analysis & 2 & & 3 & 5 \\
- reduction & 1 & 2 & 1 & 4 \\
\hline
\end{tabular}

Table 2: Types of problem sequence strategies used by informants. 


\section{ENCLOSURE: TEXT}

The informants were asked to translate the following text:

Den britisk/franske Concorde flyver i de kommende uger ind $i$ en uvis fremtid nøje overvåget af den britiske regering, som til efteråret træffer afgørelse om Concordeprojektets skæbne.

40.000 engelske arbejdere spørger for øjeblikket om deres arbejde har været forgæves, eller om deres tekniske uhyre skal blive medlem af de internationale flyselskabers flypark om 3-4 år.

I næste uge begynder Concorden 2.fase af sine prøveflyvninger. De skal bringe flyet op på en hastighed på $2.160 \mathrm{~km}$ i timen. Så vil briterne konstatere hvad et supersonisk brag vil sige, når maskinen flyver ned gennem en korridor mellem Irland og England.

\section{Translation:}

In the course of the next few weeks the Anglo-French Concorde will be flying into an uncertain future carefully surveyed by the British government which will decide on the fate of the Concorde project this autumn.

At the moment 40,000 English workers are asking themselves whether their work has been in vain or whether their technical monster will join international airlines' fleet of aircraft in three to four years.

Next week the Concorde starts its second phase of test flights. They will take the aircraft to a speed of 2,160 kilometres per hour. Then the British will realise what a supersonic bang is when the aircraft flies through a corridor between Ireland and England. (translated by the authors).

\section{Notes}

1. See Krings 1986: 120-152 for an in-depth discussion of problem indicators.

2. This classification is based on Krings 1986 which is again based on Færch $\mathrm{Cl}$. and G. Kasper 1980: "Processes and Strategies in Foreign Language Learning", ISBU, 5, pp. 47-118.

3. The protocol examples below are all word-for-word translations from Danish into English. No attempt has been made to make the language more elegant than it was in Danish; the sometimes rather clumsy language is therefore intentional. The use of bold type indicates that this word/phrase was actually said in English by the informant.

\section{REFERENCES}

ANDERSON, J. R. (1985): Cognitive Psychology and its Implications, New York.

BIALYSTOK, E. (1982): "On the Relationship between Knowing and Using Linguistic Forms", Applied Linguistics, 3-3, pp. 181-206.

BÖRSCH, S. (1986): "Introspective Methods in Research on Interlingual and Intercultural Communication", J. House and S. Blum-Kulka (Eds), Interlingual and Intercultural Communication. Discourse and Cognition in Translation, Tübingen, pp. 195-210.

ERICSSON, K. A. and H. A. SIMON (1987): "Verbal Reports on Thinking", Færch and Kasper (Eds), Introspection in Second Language Research, Clevedon/Philadelphia.

FæRCH, C. and G. KASPER (1986): "One Learner - Two Languages: Investigating Types of Interlanguage Knowledge", House and Blum-Kulka (Eds), Interlingual and Intercultural Communication. Discourse and Cognition in Translation, Tübingen.

FÆRCH, C. and G. KASPER (Eds) (1987): Introspection in Second Language Research, Clevedon/Philadelphia.

GLAHN, E., JENSEN, K. A. and L. R. JENSEN (1988): "Modeller i fremmedsprogstilegnelsen”, SAML, 13, pp. $129-164$.

JOHNSON-LAIRD, P. N. (1988): The Computer and the Mind, London.

JÄÄSKELÄINEN, R. and S. TIRKKONEN-CONDIT (1991): "Automatised Processes in Professional versus Non-Professional Translation: A Think-Aloud Protocol Study", Language in Performance, 5, Tübingen, pp. 89-111.

KRINGS, H. P. (1986): Was in den Köpfen von Übersetzern vorgeht. Eine empirische Untersuchung zur Struktur des Übersetzungsprozesses an fortgeschrittenen Französischlernern, Tübingen. 
LÖRSCHER, W. (1991): "Thinking-Aloud as a Method for Collecting Data on Translation Processes", Language in Performance, 5, Tübingen, pp. 67-79.

MCLAUGHLIN, B. (1987): Theories of Second Language Learning, London.

MONDAHL, M. and K. A. JENSEN (1989): "Regler og regelmæssighed Elevers vidensforarbejdning i en oversættelsesopgave", SAML, 14, pp. 127-154.

MONDAHL, M. and K. A. JENSEN (1992): "Information Processing in a Translation Task", Multilingua, 11-2, pp. 195-215.

MONDAHL, M. (1991): "On Learners' Use of Linguistic Knowledge in Relation to a Translation Task", ARK, 58.

RASMUSSEN, J. (1987): Mental Models and the Control of Actions in Complex Enironments, Ris $\emptyset$.

TIRKKONEN-CONDIT, S. (Ed.) (1991): "Empirical Research in Translation and Intercultural Studies", Language in Performance, 5, Tübingen. 